\title{
Does Inhaled Corticosteroids Increase the Risk of Nontuberculous Mycobacteria Pulmonary Disease: A Meta-Analysis
}

\author{
Yuanyuan Niu ${ }^{1}$, Wei Shui ${ }^{1}$, Hao Lina ${ }^{1}$, Yanli Xing ${ }^{1}$, Changran Zhang ${ }^{1}$ and Jianfeng Li $^{2 *}$ \\ ${ }^{1}$ Department of Respiratory Medicine, The Eastern Hospital of The First Affiliated Hospital, Sun Yat-sen University, China \\ ${ }^{2}$ Department of Radiation Oncology, The First Affiliated Hospital of Guangzhou Medical University, China
}

*Corresponding author: Jianfeng Li, Department of Radiation Oncology, The First Affiliated Hospital of Guangzhou Medical

University, Guangzhou, Guangdong Province, China

\section{ARTICLE INFO}

Received: 幽 October 29, 2021

Published: November 09, 2021

Citation: Yuanyuan Niu, Wei Shui, Hao Lina, Yanli Xing, Changran Zhang, Jianfeng Li. Does Inhaled Corticosteroids Increase the Risk of Nontuberculous Mycobacteria Pulmonary Disease: A Meta-Analysis. Biomed J Sci \& Tech Res 39(5)-2021. BJSTR. MS.ID.006363.

Keywords: Inhaled Corticosteroids (ICS); Nontuberculous Mycobacteria Pulmonary Disease (NTM-PD); Risk; Meta-Analysis

Abbreviations: ICS: Inhaled Corticosteroids; ORs: Odds Ratio; NTM-PD: Nontuberculous Mycobacteria Pulmonary Disease; ICS: Inhaled Corticosteroids; COPD: Chronic Obstructive Pulmonary Disease; TB: Tuberculosis

\begin{abstract}
Purpose: The usage of Inhaled Corticosteroids (ICS) has been showed to increase the risk of pneumonia and tuberculosis. However, whether the usage of ICS increases the risk of Nontuberculous Mycobacteria Pulmonary Disease (NTM-PD) remains unclear. Hence, the aim of the current meta-analysis was to define the risk of NTM-PD with the usage of ICS among chronic respiratory patients.
\end{abstract}

Methods: The PubMed, EMBASE and Web of Science databases were applied to identify eligible studies until Nov. 18, 2019. Studies focusing on the correlation between ICS and NTM-PD among chronic respiratory patients were concluded. Odds Ratio (ORs) with $95 \%$ confidence intervals (95\% CIs) were extracted and synthesized to evaluate the risk of NTM-PD with the usage of ICS. Heterogeneity was assessed by using Cochran $\mathrm{Q}$ and I-square statistics. Sensitivity and subgroup analysis were performed to trace the source of heterogeneity.

Results: A total of 5 studies with 20968 chronic respiratory patients were enrolled in current meta-analysis. The pooled OR for the risk of NTM-PD with the usage of ICS was 1.97 (95\% CI: $1.45-2.67, \mathrm{I} 2=77.3 \%, \mathrm{P}=0.001)$. In sensitivity analysis, Bual's study was the origin of heterogeneity. In the subgroup analysis, there was a trend towards the increased risk of NTM-PD with the usage of ICS among asthma and COPD patients. In addition, high-dose and current usage of ICS could increase the risk of NTM-PD.

Conclusion: A positive relationship was observed between the usage of ICS and the risk of NTM-PD. In the future, the selection of ICS should be more cautious.

\section{Introduction}

Inhaled Corticosteroids (ICS) has been widely used for the treatment of chronic respiratory diseases, especially Chronic Obstructive Pulmonary Disease (COPD) and asthma, in order to improve symptoms, reduce airway inflammation, limit further disease progression. ICS is delivered directly to lungs and therefore ICS may increase the susceptibility of local (lung) infections. Some studies have confirmed that long-term usage of ICS might result in some adverse effects, including increases in the incidence of pneumonia [1,2], oropharyngeal candidiasis [3] and Tuberculosis (TB) [4]. Corticosteroids can attenuate cellular immunity against intracellular pathogens, including mycobacteria, and raise the potential of predisposing patients to the incidence and persistence of Nontuberculous Mycobacteria (NTM) infections. Recent studies 
suggested that the presence of chronic respiratory diseases were associated with an increased likelihood of NTM Pulmonary Disease (NTM-PD) [5,6]. Some studies also reported that there was a significantly increased odds of NTM-PD among chronic respiratory disease patients who were exposed to ICS, especially fluticasone [79].

On one hand, current usage of ICS was reported to be associated with significantly increased risk of NTM-PD compared with nonusage, and this risk was showed to have a strong dose response relationship [10,11]. On the other hand, NTM-PD could make the original chronic respiratory diseases more difficult to treat, especially in older individuals with more severe airflow obstruction and greater exposure to inhaled corticosteroids [7]. However, the sample sizes of the above studies were relatively modest, and the results were inconclusive. Therefore, it seemed worthy to conduct a meta-analysis to assess the risk of NTM-PD with the usage of ICS among chronic respiratory disease patients. This study also further explored the relationship between the dosage/exposure of ICS and the risk of NTM-PD.

\section{Methods}

\section{Search Strategy}

The present study was performed according to the Preferred Reporting Items for Systematic Reviews and Meta-Analysis (PRISMA) guideline. Comprehensive literature search was conducted in the following databases, including PubMed, EMBASE and Web of Science. No language or data restrictions were imposed and the searching was updated to Nov. 18, 2019. The keywords of searching included "Mycobacterium" or "Nontuberculous" and "Inhaled corticosteroids" or "Inhaled steroids". Meanwhile, reference lists of retrieved articles were examined manually to further identify the potentially relevant publications. If analysis was based on the same patients' origin, only the latest research was considered.

\section{Selection Criteria}

The inclusion criteria for eligible studies include:

a) Clear chronic respiratory disease diagnosed by specialist

b) Meet the American Thoracic Society (ATS)/Infectious Diseases Society of America (IDSA) 2007 criteria for defining NTM -PD [12]

c) Reported the association between the ICS and NTM-PD

d) Had an odds ratio (OR) with a 95\% confidence interval (CI) or provided data for calculating OR with its corresponding 95\% CI.

Furthermore, studies were excluded according to the following criteria: a) Case reports, reviews and comments

b) Without full-text

c) Duplicate or irrelevant or nonhuman research

d) Patients were not divided into two groups, including the usage of ICS and non-usage of ICS

e) Insufficient data could be extracted to calculate the OR and 95\%CI.

\section{Data Extraction and Quality Assessment}

The full texts of the selected studies were carefully reviewed, and data were extracted by two independent researchers. A third investigator was consulted to resolve inconsistencies. The following data were extracted: the first author's name, year of publication, country of research, sample size, study type, diseases, NTM pathogens, ICS types, ICS exposure, ICS dosage and OR. The Newcastle-Ottawa Scale (NOS) was used to assess the study quality. The selection, comparability and exposure were evaluated. The scores according to NOS varied from 0 to 9 . A score of 6 or more was recognized as high quality. The NOS was used to assess the equality of each selected study by two independent authors.

\section{Statistical Analysis}

Statistical analyses of this meta-analysis were fulfilled using Stata version 12.0 (Stata Corporation, College Station, TX, USA). Pooled ORs and 95\% CIs were used to evaluate the risk of NTMPD caused by ICS among chronic respiratory disease patients. The heterogeneity across studies was tested by Cochran's Q and Higgins I2 statistics. $\mathrm{P}<0.05$ and I $>50 \%$ were considered to be significant heterogeneity, while I $<25 \%$ and $25 \%<$ I $2<50 \%$ indicated no heterogeneity and moderate heterogeneity, respectively. A random effects model was used when statistical heterogeneity was detected ( $\mathrm{P}<0.05$, I2 > 50\%); otherwise, the fixed effects model was applied. Subgroup analysis was performed to detect the origin of the heterogeneity when the data was too heterogeneous. Additionally, sensitivity analysis was carried out by sequentially omitting individual studies at each step. If the results did not substantially alter when one study was excluded, this meant that the pooled results were stable. Publication bias was evaluated by Egger's test, and $\mathrm{P}<0.05$ indicated that a statistically significant publication bias may exist.

\section{Results}

\section{Literature Search}

The search and selection strategy were shown in Figure 1. A total of 198 studies were identified after searching in PubMed, EMBASE and Web of science. After 54 duplicates were removed, 144 studies were checked by two investigators who screened the titles and abstracts. Subsequently, 123 studies were excluded 
because they were reviews, case reports, and comments $(n=69)$, studies, 5 studies were included in this meta-analysis finally after covered irrelevant topics $(n=44)$, animal experiments $(n=5), 14$ excluding publications with no available data, 1 with all NTM without control group ( $\mathrm{n}=5)$. By reading full-text of remained 21 patients used ICS, 1 without full-text.

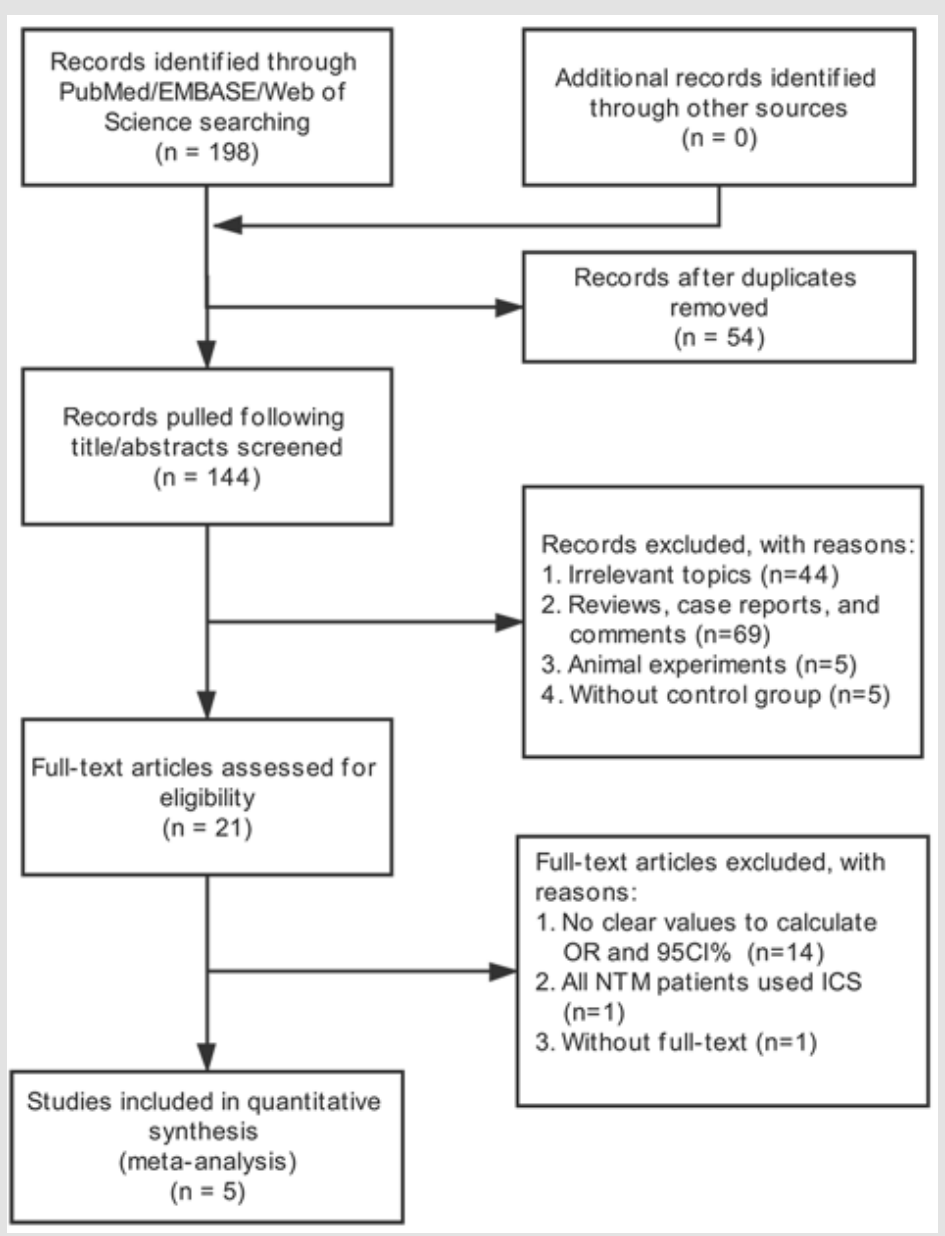

Figure 1: PRISMA flow diagram

\section{Characteristics of Eligible Studies}

The main characteristics of included studies are shown in Table 1. Totally, 5 studies with 20968 patients were included in our research. The publication dated from 2011 to 2019, and the study sample size ranged from 66 to 14817 . They were all Nested CaseControl studies. The chronic respiratory diseases were chronic obstructive pulmonary disease (COPD), asthma, bronchiectasis, cystic fibrosis and interstitial lung disease. The species causing
NTM-PD were primarily Mycobacterium avium complex (MAC) and M. xenopi. The exposure was the usage of ICS, described as a prescription filled for any inhaled beclomethasone, budesonide, Ciclesonide, fluticasone, fluticasone propionate, Momethasone or Triamcinolone, and defined current/prior and high-dose/lowdose. According to NOS, the studies quality score varied from 5 to 7 , which indicated that the study quality was moderate to high in Figure 2. 


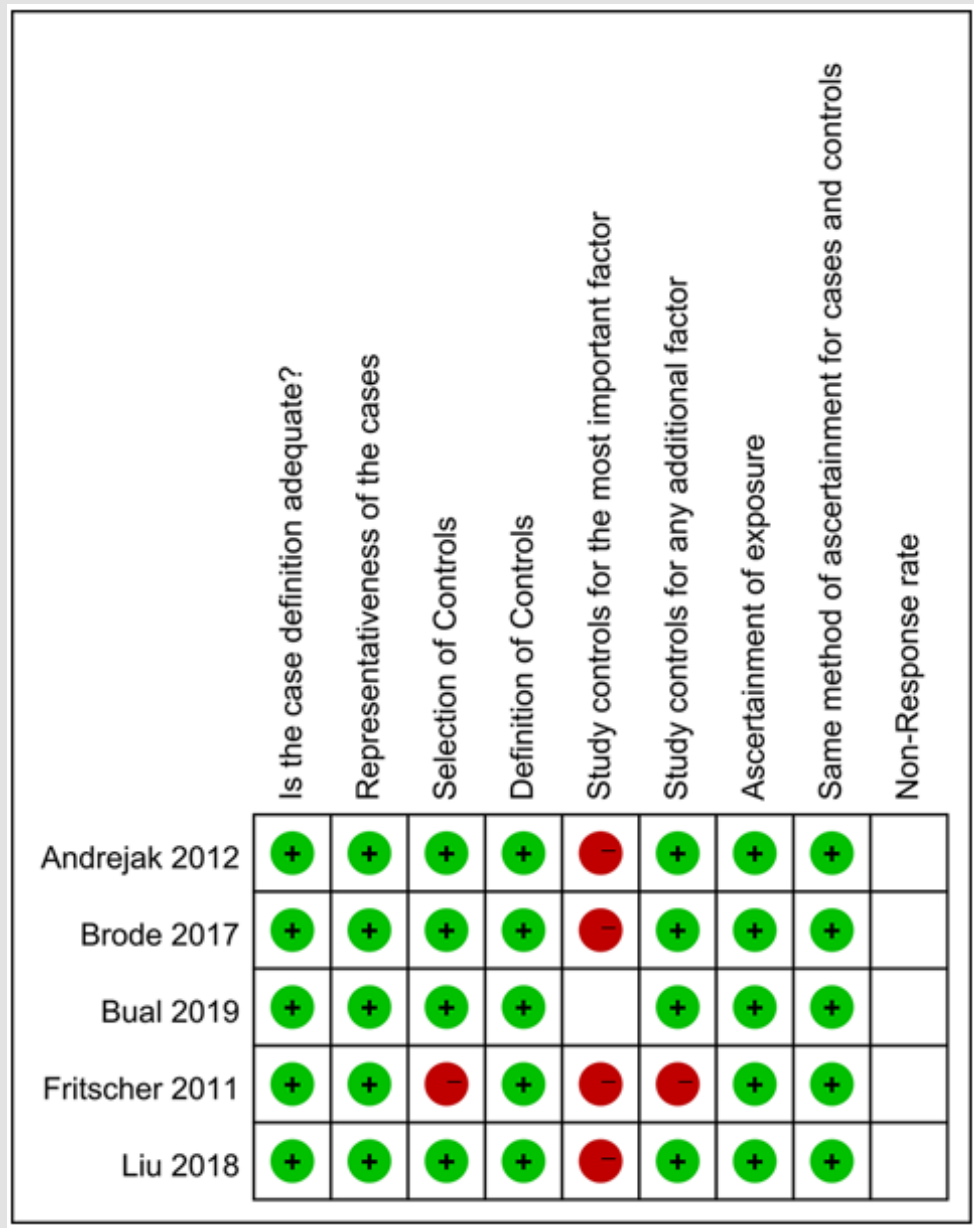

Figure 2: Risk of bias summary

Table 1: Characteristics of studies in this meta-analysis.

\begin{tabular}{|c|c|c|c|c|c|c|c|c|c|c|}
\hline Author & Year & Country & $\begin{array}{c}\text { Sample } \\
\text { Size }\end{array}$ & $\begin{array}{l}\text { Study } \\
\text { Type }\end{array}$ & Disease & $\begin{array}{c}\text { NTM } \\
\text { Pathogens }\end{array}$ & ICS Type & $\begin{array}{c}\text { ICS } \\
\text { Exposure }\end{array}$ & ICS Dose & OR \\
\hline Fritscher & 2011 & Canada & 66 & NCC & $\begin{array}{c}\text { Difficult-to- } \\
\text { Control Asthma }\end{array}$ & $\begin{array}{c}\text { MAC, } \\
\text { M. xenopi }\end{array}$ & $\mathrm{N} / \mathrm{A}$ & N/A & N/A & $\mathrm{C}$ \\
\hline Andrejak & 2012 & France & 148 & NCC & COPD, Asthma & N/A & $\begin{array}{c}\text { Beclometasone, } \\
\text { Mometasone, } \\
\text { Fluticasone, Budesonide }\end{array}$ & $\begin{array}{l}\text { Current, } \\
\text { Prior }\end{array}$ & $\begin{array}{l}\text { Low, } \\
\text { High }\end{array}$ & C \\
\hline Brode & 2017 & Canada & 14817 & NCC & $\begin{array}{l}\text { Obstructive lung } \\
\text { disease }\end{array}$ & $\begin{array}{c}\text { MAC, } \\
\text { M. xenopi and } \\
\text { other }\end{array}$ & $\begin{array}{c}\text { Beclomethasone, } \\
\text { Budesonide, } \\
\text { Ciclesonide, Fluticasone } \\
\text { propionate or } \\
\text { Momethasone }\end{array}$ & $\begin{array}{l}\text { Current, } \\
\text { Prior }\end{array}$ & $\begin{array}{l}\text { Low, } \\
\text { Moderate, } \\
\text { High }\end{array}$ & $\mathrm{C}$ \\
\hline Liu & 2018 & $\begin{array}{l}\text { United } \\
\text { States }\end{array}$ & 2728 & NCC & $\begin{array}{l}\text { COPD, Asthma, } \\
\text { Bronchiectasis }\end{array}$ & $\begin{array}{l}\text { MAC, } \\
\text { M. gordonae, } \\
\text { M. abscessus, } \\
\text { M. fortuitum } \\
\text { and other }\end{array}$ & $\begin{array}{c}\text { Beclomethasone, } \\
\text { Budesonide, } \\
\text { Flunisolide, Fluticasone, } \\
\text { Mo-metasone, or } \\
\text { Triamcinolone } \\
\end{array}$ & $\begin{array}{l}\text { Current, } \\
\text { Prior }\end{array}$ & N/A & A \\
\hline Bual & 2019 & UK & 3227 & NCC & CRD & $\mathrm{N} / \mathrm{A}$ & $\mathrm{N} / \mathrm{A}$ & Current & N/A & $\mathrm{C}$ \\
\hline
\end{tabular}

Note: NCC: Nested Case-Control study; Obstructive lung disease: Asthma, COPD, Asthma-COPD overlap syndrome; CRD: Asthma, Bronchiectasis, Cystic fibrosis, COPD, and Interstitial lung disease; MAC: Mycobacterium avium complex; N/A: not available; C: crude OR; A: adjusted OR 
Meta-analysis on ICS and NTM-PD in Chronic Respiratory

\section{Disease}

Five eligible studies (20986 patients) were included and assessed the association of the usage of ICS and the risk of NTMPD [7-11]. Since heterogeneity was found between included studies
( $\mathrm{I} 2=77.3 \%, \mathrm{P}=0.001)$, random-effect model was used. Pooled metaanalysis results demonstrated that the usage of ICS could increase the risk of NTM-PD among chronic respiratory patients $(\mathrm{OR}=1.97$, 95\% CI: 1.45-2.67) (Figure 3). We also found Bual's study was the origin of heterogeneity through sensitivity analysis (Figure 4).

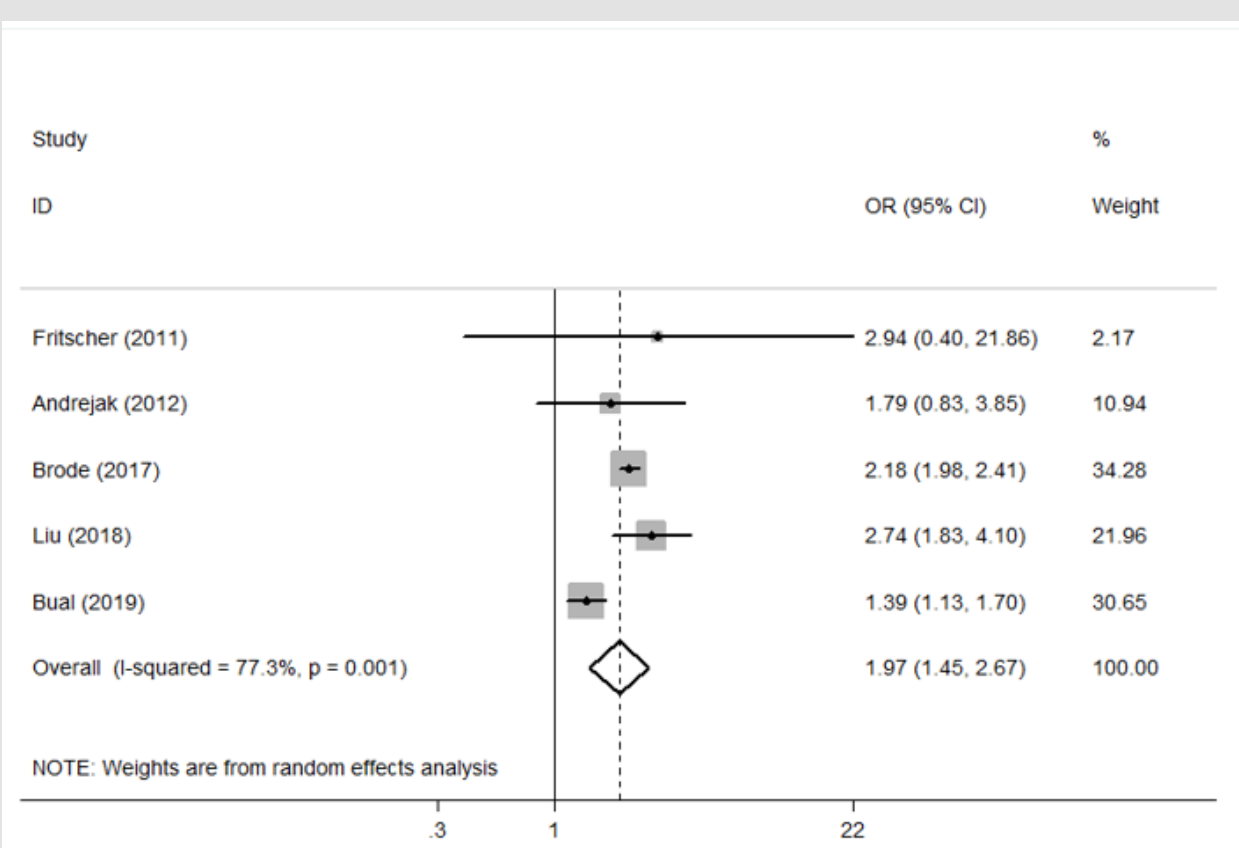

Figure 3: The relationship between ICS and NTM-PD

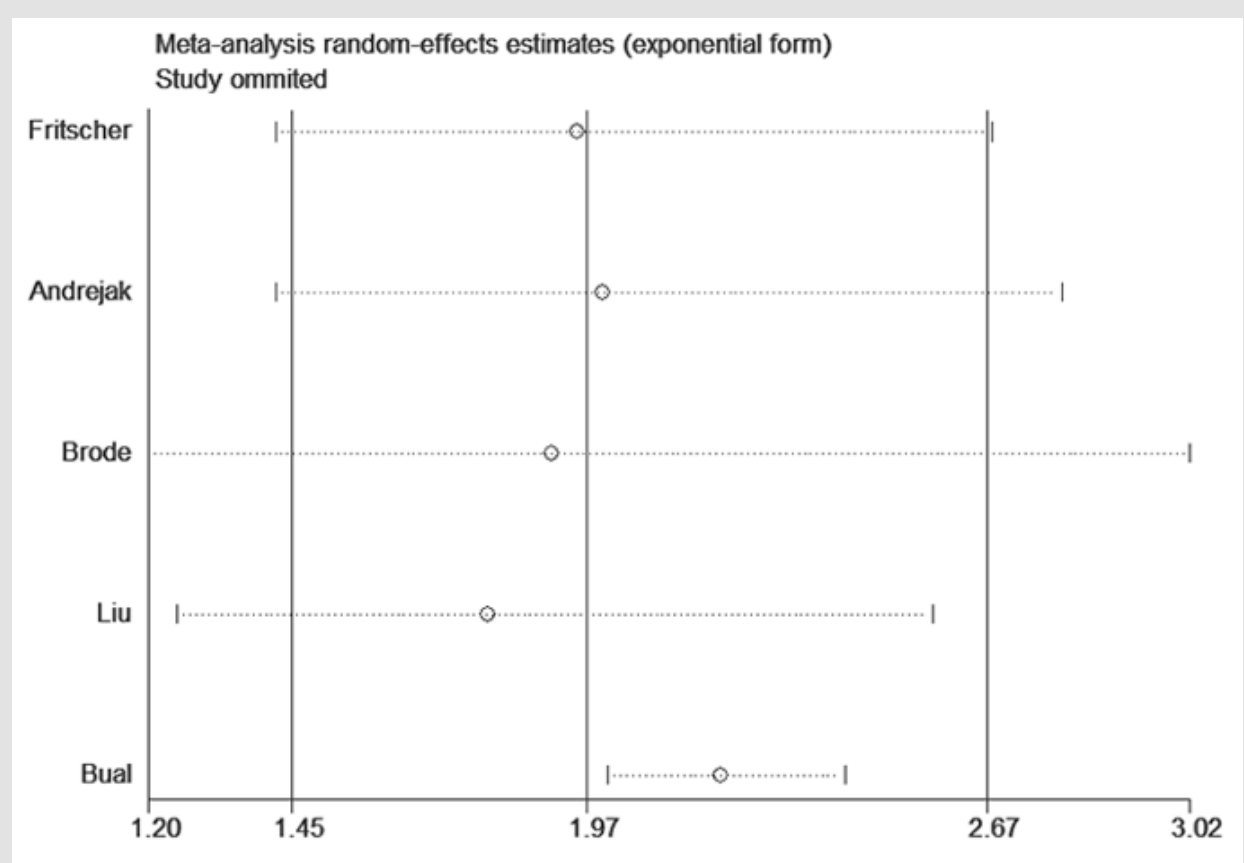

Figure 4: Sensitivity analysis 


\section{Subgroup Meta-Analysis According to Potential Confounding Factors}

Because a substantial heterogeneity existed, subgroup analyses were carried out to explore the potential sources of heterogeneity. Compared with non-usage of ICS group, an increased risk of NTMPD was showed in asthma patients used ICS (OR=1.45, 95\% CI: $1.06-1.99, \mathrm{P}=0.020)$, as well as COPD patients used ICS (OR=2.41, 95\% CI: 2.12-2.73, P=0.000) (Table 2 \& Figure 5). In addition, we observed that prior usage of ICS did not increase the risk of NTM-PD
(OR=1.30, 95\%CI: 0.61-2.77, P=0.490); However, current usage of ICS did it ( $\mathrm{OR}=1.86,95 \% \mathrm{CI}: 1.42-2.43, \mathrm{P}=0.000$ ) (Table 2 \& Figure 6). Furthermore, high-dose usage of ICS group was also associated with greater odds of NTM-PD (OR=2.29, 95\% CI: 1.95-2.69, $\mathrm{P}=0.000)$, but low-dose usage of ICS group was not (OR=1.06, 95\% CI: $0.91-1.25, \mathrm{P}=0.443$ ) (Table 2 \& Figure 7). We also observed that the OR for the risk of NTM-PD with fluticasone (OR=2.11, 95\% CI: $1.81-2.44, \mathrm{P}=0.000$ ) was higher than that with budesonide (OR=1.21, 95\% CI: 0.99-1.47, P=0.058) (Table 2 \& Figure 8).

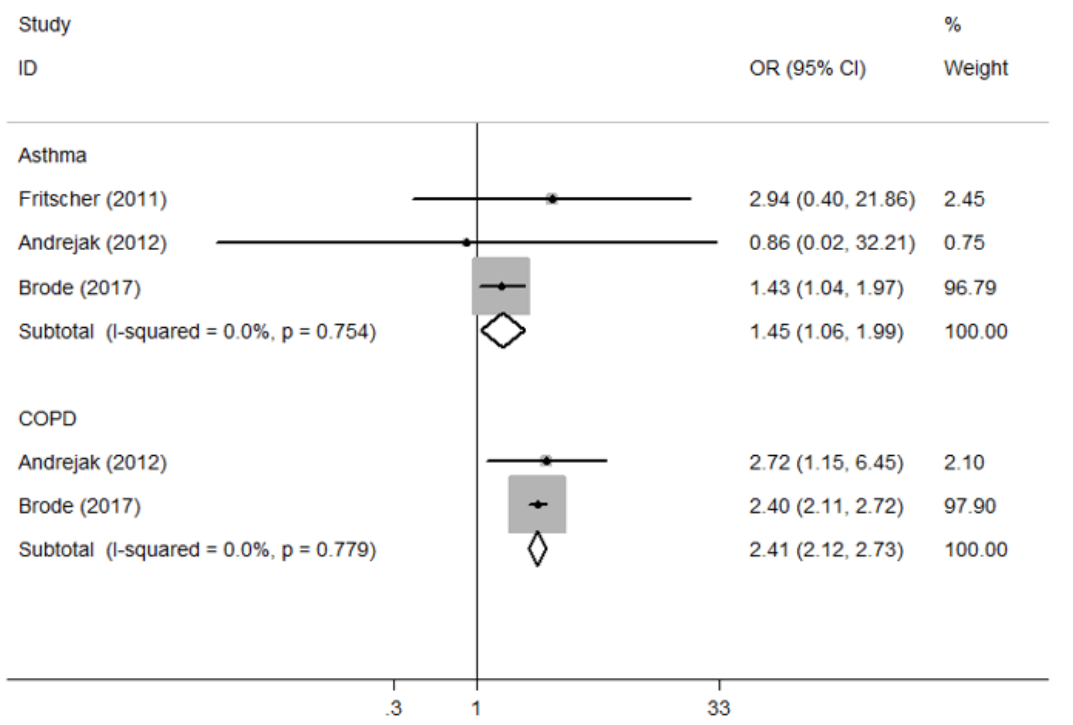

Figure 5: ICS increased the risk of NTM-PD in asthma and COPD

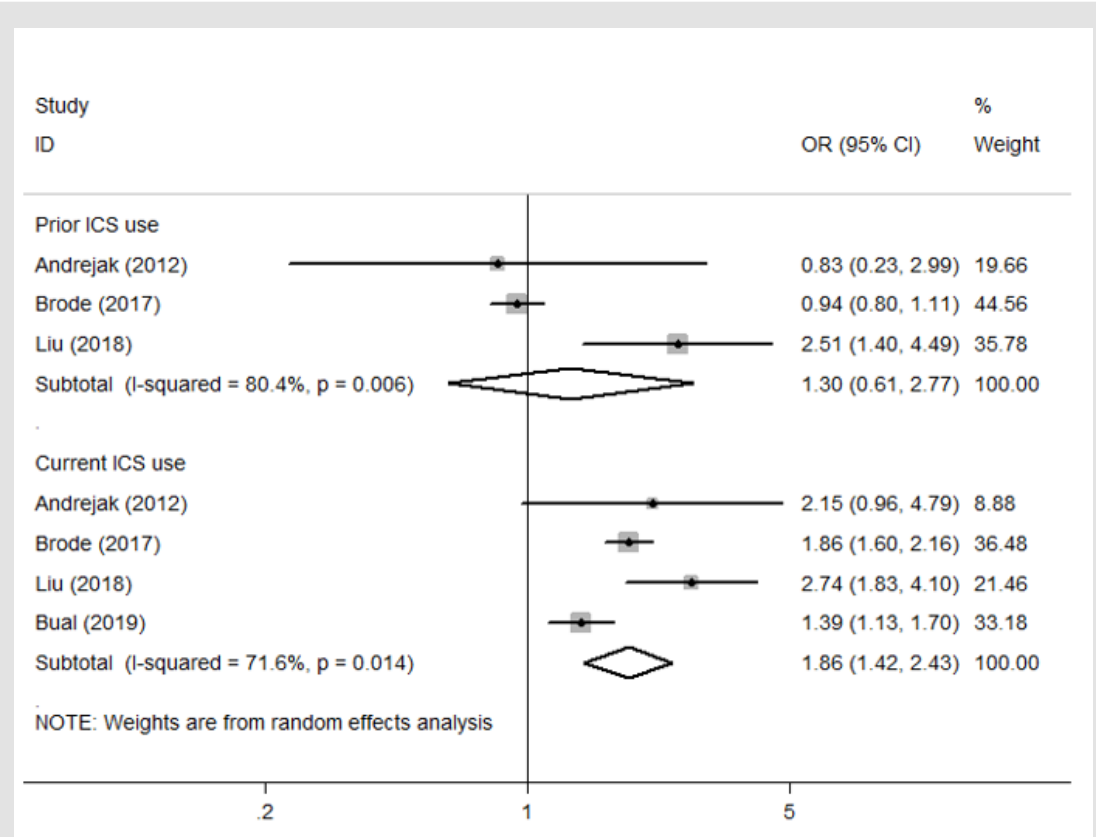

Figure 6: The relationship between ICS exposure and NTM-PD 


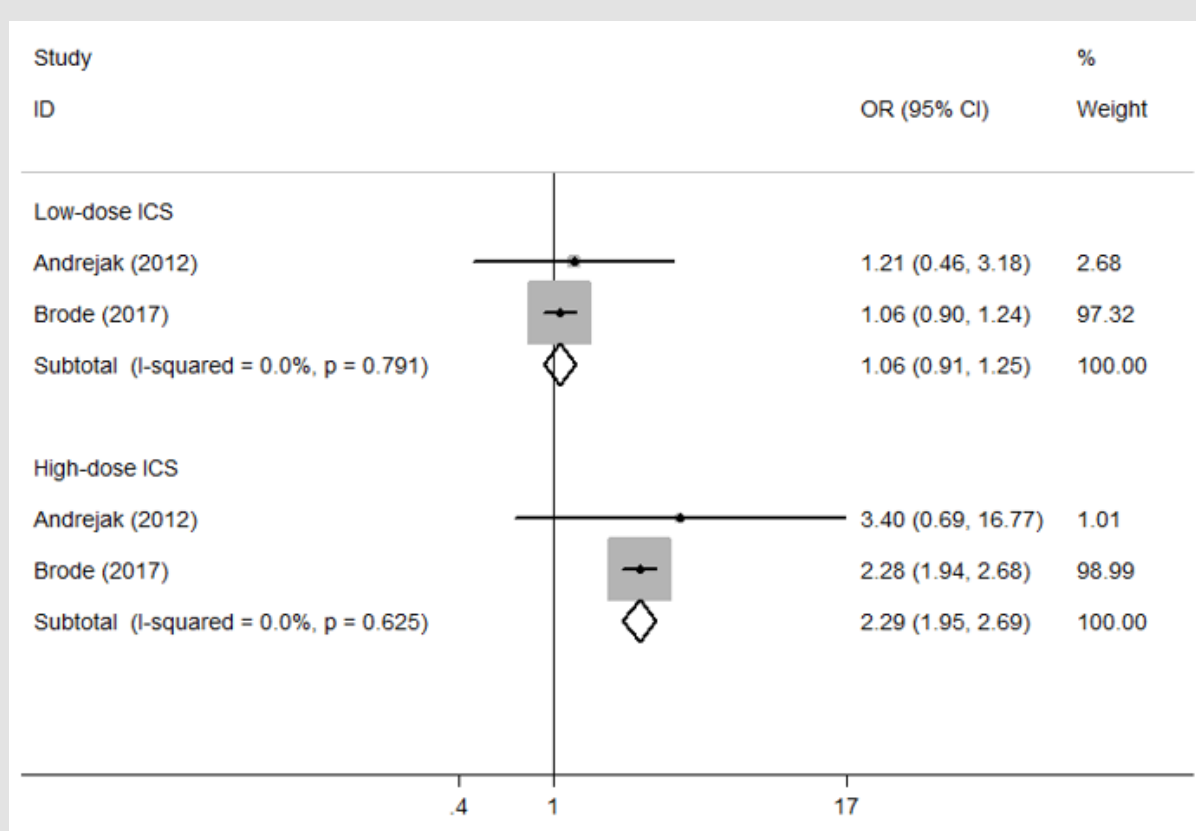

Figure 7: The relationship between ICS dose and NTM-PD

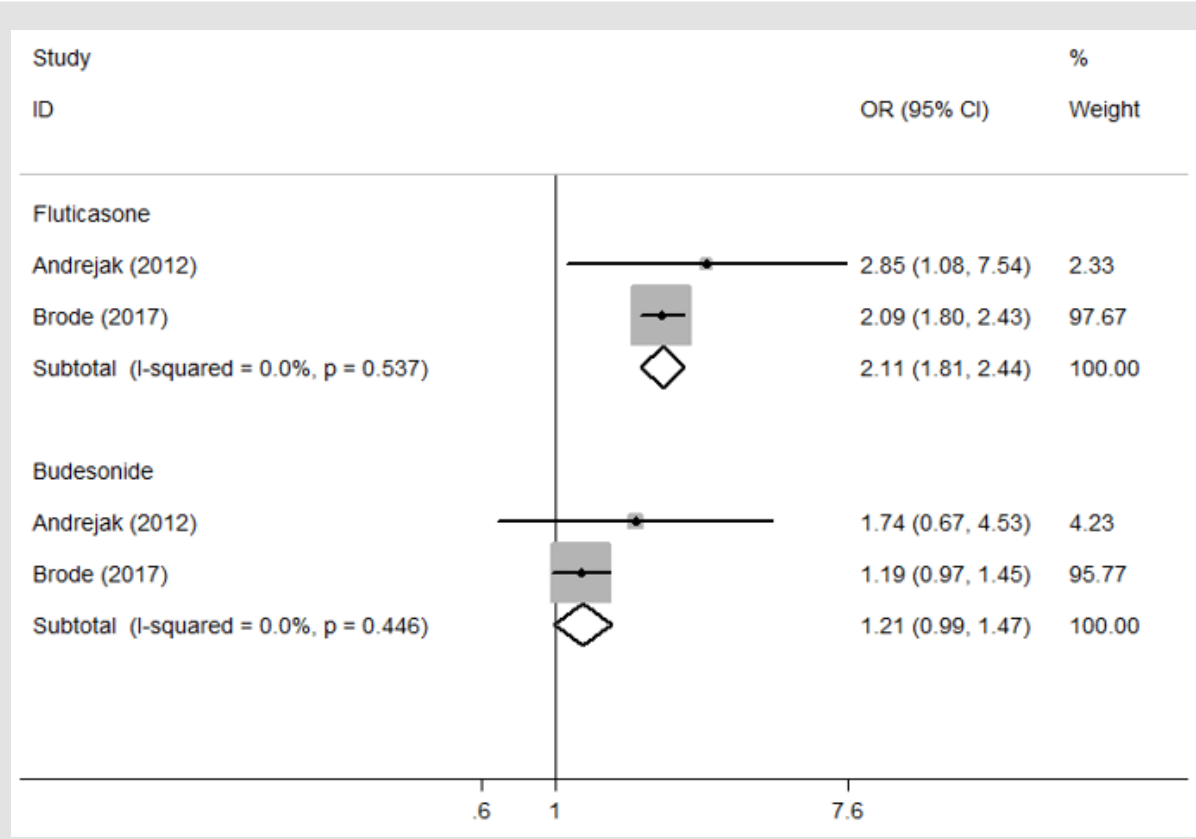

Figure 8: The relationship between ICS type and NTM-PD.

Table 2: Summary of the subgroup analysis.

\begin{tabular}{|c|c|c|c|c|c|c|c|c|}
\hline \multirow{2}{*}{$\begin{array}{l}\text { Subgroup } \\
\text { analysis }\end{array}$} & \multirow{2}{*}{$\mathbf{N}$} & \multirow{2}{*}{ References } & \multicolumn{2}{|c|}{ Random-effects model } & \multicolumn{2}{|c|}{ Fixed-effects model } & \multicolumn{2}{|c|}{ Heterogeneity } \\
\hline & & & HR $(95 \% \mathrm{CI})$ & $\mathbf{P}$ & HR $(95 \% \mathrm{CI})$ & $\mathbf{P}$ & I2 & $\mathbf{P h}$ \\
\hline \multicolumn{9}{|c|}{ Disease } \\
\hline Asthma & 3 & $7,8,10$ & $1.45(1.06-1.99)$ & 0.02 & $1.45(1.06-1.99)$ & 0.02 & $0.00 \%$ & 0.754 \\
\hline COPD & 2 & 8,10 & $2.41(2.12-2.73)$ & 0 & $2.41(2.12-2.73)$ & 0 & 0 & 0.779 \\
\hline \multicolumn{9}{|c|}{ ICS Exposure } \\
\hline Prior ICS use & 3 & $8,10,11$ & $1.30(0.61-2.77)$ & 0.49 & $1.01(0.86-1.18)$ & 0.929 & $80.40 \%$ & 0.006 \\
\hline Current ICS use & 4 & $8,9,10,11$ & $1.86(1.42-2.43)$ & 0 & $1.76(1.57-1.97)$ & 0 & $71.60 \%$ & 0.014 \\
\hline
\end{tabular}




\begin{tabular}{|l|c|c|c|c|c|c|c|c|c|}
\hline \multicolumn{7}{|c|}{ ICS Dose } \\
\hline Low-dose ICS & 2 & 8,10 & $1.06(0.91-1.25)$ & 0.443 & $1.06(0.91-1.25)$ & 0.443 & 0 & 0.791 \\
\hline High-dose ICS & 2 & 8,10 & $2.29(1.95-2.69)$ & 0 & $2.29(1.95-2.69)$ & 0 & 0 & 0.625 \\
\hline \multicolumn{7}{|c|}{ ICS Drug } \\
\hline Fluticasone & 2 & 8,10 & $2.11(1.81-2.44)$ & 0 & $2.11(1.81-2.44)$ & 0 & 0 & 0.537 \\
\hline Budesonide & 2 & 8,10 & $1.21(0.99-1.47)$ & 0.058 & $1.21(0.99-1.47)$ & 0.058 & 0 & 0.446 \\
\hline
\end{tabular}

\section{Publication Bias}

Publication bias was assessed by Egger's test. The result suggested that no asymmetry was existed (Pr $>|z|=0.854)$.

\section{Discussion}

Worldwide, pulmonary infections caused by nontuberculous mycobacteria are gaining increasing attention. NTM-PD showed relatively poor response to current multidrug therapy [13] and resulted inthe universal structural lung injury [14]. NTM-PD is more common in individuals with chronic respiratory diseases such as asthma [15], COPD [16], cystic fibrosis [17,18], bronchiectasis $[19,20]$, which may predispose to NTM infection by causing chronic epithelial cell inflammation and impaired mucociliary clearance. Recent published studies illustrated that the increasing prevalence of NTM-PD among chronic respiratory disease patients might be related to the increasing prevalent usage of ICS, which create a more favorable lung niche for NTM. ICS can impair monocyte chemotaxis, bactericidal activity, interleukin (IL) 1 and tumour necrosis factor alpha production, and $\mathrm{T}$ cell activation [21], thereby increasing the risk of NTM infections. Prior studies have suggested that the usage of ICS was associated with increases in NTM pulmonary infection. Hojo, et al. [15] evaluated a cohort of 464 asthma patients in Japan and found that NTM-PD patients received a higher daily dose of ICS (650 \pm 257 ug of fluticasone propionate equivalent) than controls (358 $\pm 273 \mathrm{ug})(\mathrm{p}<0.01)$ for a longer duration $(8.2 \pm 4.8$ vs. $5.3 \pm 4.9$ years $\mathrm{p}<0.01$ ). A recent large population-based nested case-control study from Unite States including 2728 patients also reported that any usage of ICS between 120 days and two years prior to cohort entry was associated with substantially increased odds of NTM pulmonary infection [11]. Although the above studies have investigated the inseparable relationship between ICS and NTM$\mathrm{PD}$, the sample sizes were relatively modest, and the results were inconclusive.

Our meta-analysis combined the outcomes of 20986 patients from 5 eligible studies, revealed that ICS therapy for chronic respiratory pulmonary disease, indeed increased the risk of NTMPD (OR=1.97, 95\% CI: 1.45-2.67). For patients with asthma or COPD, the usage of ICS was associated with greatly increased odds of NTM-PD, because the ICS is recommended for long-term treatment of severe asthma and in patients with advanced COPD. Our study also found that both high-dose usage of ICS and current usage of ICS might be driving the higher incidence rate of NTM-PD. In addition,
Fluticasone was associated with a greater risk of NTM-PD than budesonide. The differential risk of NTM-PD posed by fluticasone and budesonide was likely due to differences in pharmacokinetic and pharmacodynamic properties [22]. Fluticasone has a greater effect on glucocorticoid receptors, is more lipophilic and has a longer half-life than budesonide [23]. The pathophysiological mechanisms that contribute to an increased susceptibility to NTM-PD in patients treated with ICS are unclear. The usage of ICS could diminish cytokine production and CD8T cell activation among severe COPD patients [24], while CD8T cells were essential for protective immunity in nontuberculous mycobacteria [25]. Mucosal-associated invariant T (MAIT) cells were numerically and functionally deficient in NTM patients and these deficiencies could contribute to immune system dysregulation in NTM infections [26]. MAIT cells were also deficient in blood and bronchial tissue in ICS-treated, but not ICS-untreated, COPD patients [27]. Besides, previous studies showed that IFN $-\gamma$ production by NK cells played an important role in activating and enhancing innate and adaptive immune responses at early stage of pulmonary NTM infections [28]. Furthermore, the earlier reports had demonstrated that in vitro treatment with inhaled fluticasone propionate significantly decreased NK cell activities [29].

There are some limitations in our study. First, most studies only followed less stringent microbiological criteria, which might lead to overestimation of their risk of NTM pulmonary disease, despite all of studies based on ATS/IDSA criteria. Second, in subgroup analysis, there were different definitions regarding current/prior ICS exposure and high-dose/low-dose ICS, which might reduce the effectiveness of polled ORs. Third, crude OR was provided in most studies, but not adjusted OR, which might be more susceptible to confounding factors. Fourth, the eligible studies were relatively small and retrospective in design. Finally, Egger's test has relatively lower power when the number of studies included in meta-analysis less than 10 . Hence, the publication bias might not be detected by Egger's test.

\section{Conclusion}

Based on this study, it can be concluded that patients with chronic respiratory diseases, particularly asthma and COPD treated with ICS, are at highly increased risk of NTM-PD. Therefore, we believe the risk of NTM-PD should be considered when prescribing ICS, especially since NTM-PD is a chronic infection that is extremely 
difficult to treat. Clinicians should consider this risk when prescribing ICS to patients and if they are needed, strive to start from the lowest effective dose.

\section{Funding}

This research did not receive any specific grant from funding agencies in the public, commercial, or not-for-profit sectors.

\section{Conflicts of Interest}

The authors declare no conflict of interests.

\section{References}

1. Festic E, Scanlon PD (2015) Incident pneumonia and mortality in patients with chronic obstructive pulmonary disease. A double effect of inhaled corticosteroids? American journal of respiratory and critical care medicine 191(2): 141-148.

2. Drummond MB, Dasenbrook EC, Pitz MW, David J Murphy, Eddy Fan (2008) Inhaled corticosteroids in patients with stable chronic obstructive pulmonary disease: a systematic review and meta-analysis. Jama 300(20): 2407-2416.

3. Yang IA, Clarke MS, Sim EHA, Wun M Fong (2012) Inhaled corticosteroids for stable chronic obstructive pulmonary disease. Cochrane Database of Systematic Reviews 7: CD002991.

4. Brassard P,Suissa S, Kezouh A, Pierre Ernst (2011) Inhaled corticosteroids and risk of tuberculosis in patients with respiratory diseases. American journal of respiratory and critical care medicine 183(5): 675-678.

5. Marras TK, Vinnard C, Zhang Q Keith Hamilton, Jennifer Adjemian, et al. (2018) Relative risk of all-cause mortality in patients with nontuberculous mycobacterial lung disease in a US managed care population. Respiratory medicine 145: 80-88.

6. Cowman S, Van Ingen J, Griffith DE, Michael R Loebinger (2019) Nontuberculous mycobacterial pulmonary disease. European Respiratory Journal 54: 1900250 .

7. Fritscher LG, Marras TK, Bradi AC, Meyer S Balter, Kenneth R Chapman, et al. (2011) Nontuberculous mycobacterial infection as a cause of difficult-to-control asthma: a case-control study. Chest 139(1): 23-27.

8. Andréjak C, Nielsen R, Thomsen V $\varnothing$, Henrik Toft Sørensen, Reimar Wernich Thomsen, et al. (2013) Chronic respiratory disease, inhaled corticosteroids and risk of non-tuberculous mycobacteriosis. Thorax 68(3): 256-262.

9. Axson EL, Bual N, Bloom CI, Jennifer K Quint (2019) Risk factors and secondary care utilization in a primary care population with nontuberculous mycobacterial disease in the UK. European Journal of Clinical Microbiology \& Infectious Diseases 38(1): 117-124.

10. Brode SK, Campitelli MA, Kwong JC, Hong Lu, Alex Marchand-Austin, et al. (2017) The risk of mycobacterial infections associated with inhaled corticosteroid use. European Respiratory Journal 50(3): 1700037.

11. Liu VX, Winthrop KL, Lu Y, Hekmat U Nasiri, Stephen J Ruoss, et al. (2018) Association between Inhaled corticosteroid use and pulmonary nontuberculous mycobacterial infection. Annals of the American Thoracic Society 15(10): 1169-1176.

12. Griffith DE, Aksamit T, Brown Elliott BA, Antonino Catanzaro, Charles Daley, et al. (2007) An Official ATS/IDSA Statement: Diagnosis, Treatment, and Prevention of Nontuberculous Mycobacterial Diseases. American Journal of Respiratory and Critical Care Medicine 175(4): 367416.

13. Shulha JA, Escalante P, Wilson JW (2019) Pharmacotherapy Approaches in Nontuberculous Mycobacteria Infections. Mayo Clinic Proceedings. Elsevier 94(8):1567-1581.
14. Haworth CS, Banks J, Capstick T, Robert Wilson, R Andres Floto, et al. (2017) British Thoracic Society guidelines for the management of non-tuberculous mycobacterial pulmonary disease (NTM-PD). Thorax 72(Suppl): 1-64.

15. Hojo M, Iikura M, Hirano S, Nobuyuki Kobayashi, Koichiro Kudo, et al. (2012) Increased risk of nontuberculous mycobacterial infection in asthmatic patients using long-term inhaled corticosteroid therapy. Respirology 17(1): 185-190.

16. Marras TK, Campitelli MA, Kwong JC, Andrea S Gershon, Frances B Jamieson, et al. (2016) Risk of nontuberculous mycobacterial pulmonary disease with obstructive lung disease. European Respiratory Journal 48(3): 928-931.

17. Qvist T, Pressler T, Taylor-Robinson D, Terese L Katzenstein, Niels Høiby et al. (2015) Serodiagnosis of Mycobacterium abscessus complex infection in cystic fibrosis. European Respiratory Journal 46(3): 707716.

18. Adjemian J, Olivier KN, Prevots DR (2014) Nontuberculous Mycobacteria among Patients with Cystic Fibrosis in the United States. Screening Practices and Environmental Risk. American Journal of Respiratory \& Critical Care Medicine 190(5): 581-586.

19. Shteinberg M, Stein N, Adir Y, Leonardo Fuks, Walid Saliba, et al. (2018) Prevalence, risk factors and prognosis of Nontuberculous mycobacteria infection among people with bronchiectasis: a population survey. European Respiratory Journal 51(1): 1702469.

20. Henkle E, Aksamit TR, Barker AF, Susan Wisclenny, Kevin L Winthrop, et al. (2017) Pharmacotherapy for Non-Cystic Fibrosis Bronchiectasis: Results From an NTM Info \& Research Patient Survey and the Bronchiectasis and NTM Research Registry. Chest 152(6): 1120-1127.

21. Barnes PJ (2006) Corticosteroid effects on cell signalling. European Respiratory Journal 27(2): 413-426.

22. Suissa S, Patenaude V, Lapi F, Pierre Ernst (2013) Inhaled corticosteroids in COPD and the risk of serious pneumonia. Thorax 68(11): 1029-1036.

23. Derendorf H, Nave R, Drollmann A, F Cerasoli, W Wurst (2006) Relevance of pharmacokinetics and pharmacodynamics of inhaled corticosteroids to asthma. European Respiratory Journal 28(5): 1042-1050.

24. Zhu X, Gadgil A S, Givelber R, M Patricia George, Michael W Stoner, et al. (2009) Peripheral T cell functions correlate with the severity of chronic obstructive pulmonary disease. The Journal of Immunology 182(5): 3270-3277.

25. Shu CC, Wu LSH, Wu MF, Hsin-Chih Lai, Ping-Huai Wang, et al. (2019) Mono-and poly-functional $\mathrm{T}$ cells in nontuberculous mycobacteria lung disease patients: Implications in analyzing risk of disease progression. Cytokine 120: 176-185.

26. Kwon YS, Cho YN, Kim MJ, Hye-Mi Jin, Hyun Ju Jung, et al. (2015) Mucosal-associated invariant $\mathrm{T}$ cells are numerically and functionally deficient in patients with mycobacterial infection and reflect disease activity. Tuberculosis 95(3): 267-274.

27. Hinks TSC, Wallington JC, Williams AP, Ratko Djukanović, Karl J Staples, et al. (2016) Steroid-induced deficiency of mucosal-associated invariant $\mathrm{T}$ cells in the chronic obstructive pulmonary disease lung. Implications for non-typeable Haemophilus influenzae infection. American journal of respiratory and critical care medicine 194(10): 1208-1218.

28. Lai HC, Chang CJ, Lin CS, John D Young, Chia Chen Lu, et al. (2018) NK Cell-Derived IFN- $\gamma$ Protects against Nontuberculous Mycobacterial Lung Infection. The Journal of Immunology 201(5): 1478-1490.

29. Di LG, Esposito PM, Drago A, C Balistreri, F Listi, et al. (2001) Effects of in vitro treatment with fluticasone propionate on natural killer and lymphokine-induced killer activity in asthmatic and healthy individuals. Allergy 56(4): 323-327. 
ISSN: 2574-1241

DOI: 10.26717/BJSTR.2021.39.006363

Jianfeng Li. Biomed J Sci \& Tech Res

(C) (P) This work is licensed under Creative Commons Attribution 4.0 License

Submission Link: https://biomedres.us/submit-manuscript.php

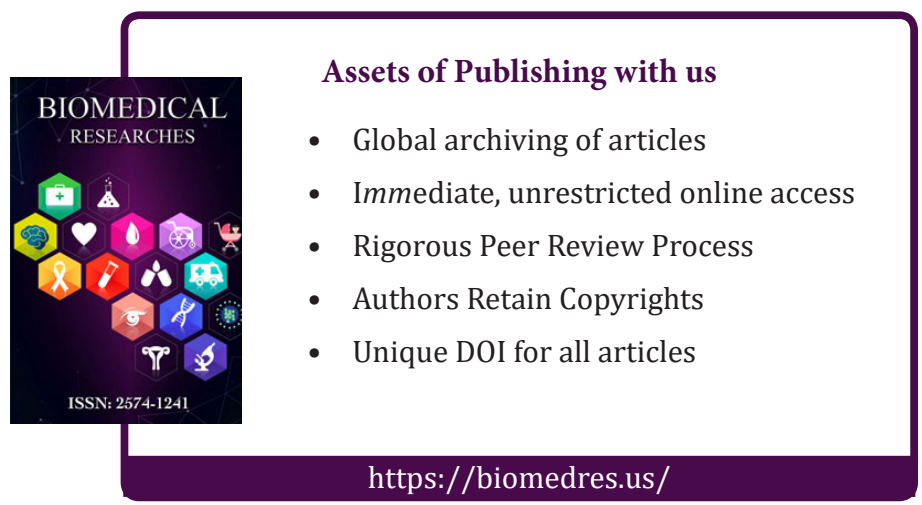

